\title{
Study of correlations between yield inheritance and resistance of corn self-pollinating lines and hybrids to pathogens
}

\author{
O. M. Kolisnyk ${ }^{*}$, V. P. Onoprifienko², I. M. Onopriienko², N. M. Kandyba², L. M. \\ Khomenko ${ }^{2}$, T. O. Kyrychenko ${ }^{2}$, D. S. Tymchuk ${ }^{3}$, N. F. Tymchuk ${ }^{4}$, N. O. Terokhina ${ }^{2}$ \\ ${ }^{1}$ Vinnytsia National Agrarian University, Soniachna Str. 3, 21008, Vinnytsia, Ukraine \\ ${ }^{2}$ Sumy National Agrarian University, Gerasim Kondratyev Str. 160, 40021, Sumy, Ukraine; \\ ${ }^{3}$ Kharkiv Institute of Medicine and Biomedical Sciences, Sadovaya Str. 11,61002, Kharkiv, Ukraine \\ ${ }^{4}$ Kharkiv National Medical University, Nauky ave. 4, 61022, Kharkiv, Ukraine
}

\section{E-mail: andb201727@ukr.net}

\section{Received: 07.02.2020 Accepted 07.03.2020}

\begin{abstract}
The results of the gradation grouping of corn hybrids showed that among the self-pollinating lines of the working collection $28.0 \%$ had a high crop, $50.0 \%$ had an average yield and $22.0 \%$ had a low yield. At the same time $10.5 \%$ of simple hybrids belonged to the group with high crop, $54.6 \%$ - to that with an average one and $34.9 \%$ - to low yielders. The fact that these $10.5 \%$ of hybrid combinations with the yields higher than $5.5 \mathrm{t} \mathrm{ha}^{-1}$ contain hybrid combinations with complex resistance to diseases and pests, which were created on the basis of our self-pollinating donor lines resistant to entomo- and phytopathogens, confirms the principles we formulated as to selecting parental pairs. The most uniform distribution was recorded as to damaging by the European corn borer, a high resistance to which is characteristic of $42.0 \%$ of self-pollinating lines and $29.1 \%$ of simple hybrids.
\end{abstract}

Key words: Corn; Self-pollinating lines; Corn and loose smut; Resistance assessment; Ripeness group; Selection

\section{Introduction}

Food security is fundamental for human survival and national security. By 2050, the global population is expected to increase to 9.2 billion from 6.5 billion today (Thornton et al., 2009). Population growth and expanding consumption will drive global food demand up by $50 \%$ by 2030 , or double that of 2000 levels (Yang et al., 2017).

To meet the needs of the global population, which is expected to peak at $8.5-10$ billion in 2050, grain production must increase by at least $50 \%$ and perhaps by as much as $110 \%$ relative to production in 2006 (Tester \& Langridge, 2010; FAO, 2011; Tilman et al., 2011). In the absence of major breakthroughs in farming systems and agricultural production, the most viable strategy to ensure food security is to continuously increase crop yields (Meng et al., 2011). Maize is one of the world's most important cereals, and its production must roughly double to meet the growing demand for food, biofuel, and livestock feed, especially in developing countries (Shiferaw, et al., 2011).

In corn breeding much attention is paid to the creation of hybrids, which together with high yielding properties would be characterized by resistance to harmful organisms. Maize breeders have improved productivity through selection on phenotype (Barlog, 2008).

The introduction of such hybrids will significantly improve the cultivation of corn in the Forest-Steppe Zone of the Right-Bank Ukraine and allow obtaining resistant hybrids to diseases and pests. Corn is a crop that dominates the global grain production. The total area of 162 million hectares produces about 850 million tons of corn, with an average yield of $5.2 \mathrm{t}$ ha-1. The world's grain production of this crop has increased to a record 850 million tons in recent years, with $39.0-46.2 \%$ of it being harvested in the United States and high croppage in China and Brazil (Palamarchuk, 2018; Tanchik, 2009; Troyer, 2004.).

In Ukraine corn occupies an area of 4.5-5.0 million hectares, which makes up almost a quarter of all cereals. On 4.0-4.5 million hectares it is harvested for grain and on 0.2-0.4 million hectares it is cut for silo and green fodder (Palamarchuk et al., 2010; Kolisnyk, 2016; Scherner, 2016). The introduction of intensive technology and new highly productive hybrids has significantly increased corn yield in large areas. Many of the best farms receive 9-10 t ha and more, including new areas of corn sowing (Polissia of Ukraine). In some regions of Ukraine the yield is 5.5-6.0 t ha, however, in general corn production remains low and entomo- and phytopathogens are an immediate cause of it (Zozulia et al., 1983; Palamarchuk et al., 2009; Butenko et al., 2019).

The genotypic components being the heritable part of the total variability, since it influences the selection strategies to be adopted by the breeder. The success of selection depends on the choice of selection criteria. Yield components do not only directly affect the yield but also indirectly by affecting other yield components in negative or positive ways (Bidgoli et al., 2006; Ivanov et al., 2019). Crop yield is one of the complex characters controlled by several interacting genotypic and environmental factors. There are quite few yield components which are less complex, highly inherited and less influenced by the environmental changes (Kashiani \& Saleh, 2010). Interrelationships existed between yield and its contributing components can significantly improve the efficiency of crop breeding programmes through the use of proper selection indices (Mohammadi et al., 2003; Kashiani et al., 2010). Direct selection 
for yield is often misleading as it is highly influenced by unpredictable environmental components (Talebi et al., 2007). The correlation coefficient analysis is useful in the selection of several traits simultaneously influencing yield (Menkir, 2008). Genetic correlation analysis exploits the degree of association among important quantitative traits (Malik et al., 2005). By utilizing genetic correlations between traits, secondary traits can be used to improve primary ones that have low heritability or are difficult to measure (Malosetti et al., 2008). The purpose of the research was to develop and identify self-pollinating lines by resistance to major diseases and pests, to identify deterministic signs for the development of principles for the selection of parental pairs in the creation of corn hybrids resistant to the complex of entomo- and phytopathogens adapted to the conditions of the Forest-Steppe of the Right-Bank Ukraine (Tsiuk, 2013; Kolisnyk, 2010).

The objectives of the research were to determine the source of resistance to certain diseases and pests, as well as to identify the lines that combine high correlation dependence on the basis of sustainability with grain yield; to identify the manifestation of the effect of heterosis in simple corn hybrids by their yield and resistance to diseases and pests; to determine the degree of harmfulness of the main diseases and pests in the conditions of the Forest-Steppe of the Right-Bank Ukraine, to give an economic assessment of perspective corn hybrids cultivation (Kolisnyk, 2016; Didur et al., 2019; Kolisnyk, 2007).

\section{Materials and Methods}

We have used the following methods: field studies for individual selection in a breeding nursery, phenological observations and sampling; laboratory methods - for the analysis of plants by morphological features, genetic - for the detection of breeding and genetic features of corn lines in the creation of hybrids of different maturity groups under the use of monoculture with combination of valuable economic features with resistance to disease and pests; statistical - to establish patterns of variability of signs and degree of reliability between the variants of experience; a comparative- calculation method - to determine cost effectiveness.

In Vinnytsia region, where the research zone is located, the climate is moderately warm. Winter begins in the second or third decade of November. Snow cover forms on average in the third decade of December and melts away in the third decade of March. Its height in the western and southern parts of the zone ranges from $13-20 \mathrm{~cm}$, and in the eastern part it can vary from $26-35 \mathrm{~cm}$. The average monthly temperature in January and February varies from -4.0 to $-8.0^{\circ} \mathrm{C}$. This zone is characterized by long thaws, during which the air temperature in some years rises to $+12-14^{\circ} \mathrm{C}$.

Spring lasts from 65 to 75 days. The temperatures above $5^{\circ} \mathrm{C}$ degrees are set in the first decade of April. Summer is characterized by high and stable temperatures. The average monthly temperature in July varies from $+10^{\circ} \mathrm{C}$ in the west to $-20^{\circ} \mathrm{C}$ in the east. The absolute maximum temperature can reach $+39-49^{\circ} \mathrm{C}$. Hot winds and droughts often accompany the growing season, which lasts $150-170$ days.

According to the average multiyear annual data, corn in the research area undergoes its main phases of development in the following calendar dates: germination 20.05; 3rd leaf - 26.05; appearance of panicles - 14.07; cob flowering - 20.07; milky ripeness of grain - 22.08; wax ripeness of grain - 11.09 (Kolisnyk et al., 2019; Tsyhanskyi, 2019).

Therefore, the first two years of observation were the most favorable for the growth and development of corn by weather indicators (air temperature, precipitation). They contributed to the resistance of corn to diseases and pests as well as to the intensive growth and development of plants themselves. The third year faced a significant deterioration of the climatic conditions due to the long dry period, which occurred in the phases of panicles and cobs flowering and grain formation.

\section{Results and Discussion}

We have obtained corn hybrids that produce high and stable yields, which is one of the main tasks in corn selection.

Testing resistance of the source material to diseases and pests, we have found that the samples that combine high grain productivity with complex resistance to harmful organisms in the genotype are the most suitable for the aforementioned conditions. Weather conditions (air temperature, precipitation) influenced not only the resistance characteristics of self-pollinating lines and simple hybrids to pests and diseases, but also the growth processes of corn plants themselves in the context of their ripeness groups (Table 1).

Table 1. Manifestation of morphological features of self-pollinated corn lines.

\begin{tabular}{|c|c|c|c|c|c|c|c|c|c|}
\hline \multirow{3}{*}{$\begin{array}{l}\text { Lines } \\
\text { Early-season }\end{array}$} & \multicolumn{6}{|c|}{ Height, CM } & \multirow{2}{*}{\multicolumn{3}{|c|}{$\begin{array}{l}\text { Rainfall during the } \\
\text { growing season, mm }\end{array}$}} \\
\hline & \multicolumn{3}{|c|}{ plants } & \multicolumn{3}{|c|}{ corncob attachment } & & & \\
\hline & 119.8 & 89.2 & 116.4 & 28.5 & 19.7 & 26.5 & 381.4 & 258.2 & 274.9 \\
\hline Middle-early & 122.1 & 97.5 & 130.41 & 35.7 & 23.7 & 33.3 & 411.7 & 272.3 & 388.0 \\
\hline Mid-season & 140.3 & 115.7 & 135.0 & 39.5 & 28.9 & 38.6 & 430.6 & 293.4 & 412.5 \\
\hline TSSD0.05 & 9.72 & 9.14 & 9.09 & 4.77 & 3.81 & 3.73 & - & - & - \\
\hline
\end{tabular}

Over the research years, the amount of precipitation was higher than 551.6 and $474.9 \mathrm{~mm}$ respectively during the growing season, so the height of the plants and corncob attachment was higher. Rainfall, depending on the length of the growing season, was distributed as follows: early-season - 381, $4 \mathrm{~mm}$; middle-early $-411.7 \mathrm{~mm}$; mid-season - $430.6 \mathrm{~mm}$. The amount of rainfall during the growing season of the early-season lines $-274.9 \mathrm{~mm}$, the middle-early $-388.0 \mathrm{~mm}$, and the mid-season - $412.5 \mathrm{~mm}$. The average height of plants in the early-season group was $119.8 \mathrm{~cm}$, in the middle-early group it was $122.1 \mathrm{~cm}$, in the midseason it was $-140.3 \mathrm{~cm}$. The average height of corncob attachment was $28.5 \mathrm{~cm} ; 35.7 \mathrm{~cm}$ and $39.5 \mathrm{~cm}$ respectively.

The height of the plants and corncob attachment in the early-season group were within the range of 116.4 and $26.5 \mathrm{~cm}$, in the middle-early - 130.4 and $33.3 \mathrm{~cm}$, in the mid-season -135.0 and $38.6 \mathrm{~cm}$.

Thus, abiotic environmental factors can influence the resistant characteristics of corn genotypes both through the influence on the specifics of the pest or pathogen development as well as through the morphological features of the plants themselves and their growth rates. 
Study of the yield levels of self-pollinating lines and simple hybrids enabled to divide them into three groups: high-, average- and low-yielding. According to the results of the study of yield levels of self-pollinating corn lines (Table 2), we have found that high yields (> 2.5 t ha-1) had the following lines: V 37, SM 5-1-1, SO 91, SO 108, K 212, MA 22, Oh 43 H.t., W 401 (81), UKh 405, UKhK 411, KhLG 42, KhLG 45, KhLG 224, KhLG 562 and KhLG 1339.

Table 2. Groups of self-pollinating corn lines by yield, 2015-2017.

\section{Self-pollinating corn lines}

V 37, SM 5-1-1, SO 91, SO 108, K 212, MA 22, Oh 43H.t., W 401 (81), UKh 405, UKhK 411, KhLG 42, KhLG 45, KhLG 224, KLG 562, KhLG 1339.

$\begin{array}{ll}\begin{array}{l}\text { Yield level, } \\ \text { t ha }^{-1}\end{array} & \text { Xaverage } \pm \mathbf{S x} \\ & \\ \text { high, } & 2.97 \pm 0.114\end{array}$

AS 77-4-1, SM 7 (St), F 7 (81), F 502, K 210, KL 17, MA 17, MA 23S, MA 61 A37, PLS 61, S 35, S 38, UKhK 372, KhLG 33, KhLG 85, KhLG 163, KhLG 189, average, KhLG 272, KhLG 293, KhLG 386, KhLG 489, KhLG 1128, KhLG 1216, KhLG 1.5-2.5 1278.

SO 113, S0 255, F 101, FS 200, KL 13, MA 11, DK44-1, UKhK 409, KhLG 81, low, KhLG 294, KhLG $998 . \quad<1.5$
$<1.5 \quad 1.33 \pm 0.042$

Self-pollinating corn lines SO 113, SO 255, F 101, FS 200, KL 13, MA 11, DK 44-1, UKhK 409, KhLG 81, KhLG 294 and KhLG 998 , which are not of selection value for research in this direction, demonstrated low grain yields $(<1.5 \mathrm{~T}$ ha-1).

Thus, the source material, which has high and average yield levels, is most advisable to use by parental forms with the aim of selecting high yielding heterotic hybrids, resistant to diseases and pests.

Simple hybrids created on the basis of self-pollinating lines of the working collection also varied in levels of yield (Table 3).

Table 3. Groups of simple corn hybrids by yield, disease and pests resistance, 2016-2017.

\section{Simple hybrid}

KhLG 562/PIS61, KhLG 294/KhLG 293, UKh 405/SM5-1-1, S0113/AS77-4-1, AS 77-4-1/SO 113, MA 22/UKh 405, UKh 405/UKhK 409, SM5-1-1/UKh 405, UKh High, 405/MA 22, B 37/MA 61 A37, F 502/UKh 405, Dniprovs'kyi 284MB (st), Moldavs'kyi > 5.5 291 AMB (st).

\section{Yield level t ha-1}

$5.91 \pm 0.32$

F101/FS200, KhLG 272/KhLG 81, PLS61/KhLG 562, SO255 /UKh 405, UKhK 411/KL17, KL17/MA22, SO 91/UKhK 372, UKh 405/SO 255, SO 255/SO 108, KhLG 1216/KhLG 1278, KL 17/F 502, UKhK 409/F502, MA22/F502, SO108/SO255,SO108/SM5-1-1, SM5-1-1/SO 108, UKhK 409 x SM 5-1-1, F 502 x SO 108, MA 22 x SM 5-1-1, SM 5-1-1/MA 22, KhLG 293/KhLG 294, SO 108/F 502, KhLG 1339/KhLG 1128, SM5-1-1/F502, F502/MA 22, F 502/SM5-1-1, UKh 405/F 502, KhLG 1128/KhLG 1339, MA 22/SO 108, KL 17/SM 5-1-1, ДK44-1/KhLG , SO 108/KL 17, MA 22/KL 17, UKhK 409/KL 17, F 502/UKhK 409, F 502/KL17, UKh 405/SO 108, KhLG 42/ДК 44-1, UKhK 409/UKh 405, KL 17/UKh 405, KL 17/SO 108, UKhK 409/SO108, MA 22/UKhK 409, UKh 405/KL 17, MA 61 A37/B 37, Dniprovs'kyi 172 MB (St).

F101/MA11, MA11/F101, FS200/S 38, S 38/S 35, KhLG 81/KhLG 272, SO255/SM51-1, F502/SO255, KhLG 1278/KhLG 1216, SM5-1-1/UKhK 409,SO 255/MA 22, SM5-1-1/SO 255, UKhK 409/SO255, SO255/F 502, S 35/S 38, MA 22/SO255, SO255/KL17, KL 17/SO 255, KhLG 163/KhLG 33, SO 108/MA 22, UKhK 372/SO 91, Low, KL 13/UKhK 411, KhLG 33/KhLG 163, SO 255/UKhK 409, UKhK 409/MA 22, SM5$<4.5$ Xaverage $\pm \mathbf{S x}$ 1-1/KL 17, KhLG 85/KhLG 45, KL 17/UKhK 409, SO 108/UKh 405, SO 108/UKhK 409. 
The data shows that the group of the most productive hybrids includes those that have been created with the participation of lines that have high positive values of correlations dependency as for grain yields UKh 405, MA 22, SO 108 and others.

In addition, the results of the gradation grouping show that among the self-pollinating lines of the working collection $28.0 \%$ had high, $50.0 \%$ - average and $22.0 \%$ - low levels of yielding capacity respectively. As for simple hybrids, $10.5 \%$ of them belonged to the group with high yield, $54.6 \%$ - to average, and $34.9 \%$ - to a low yield group. That fact that these $10.5 \%$ of hybrid combinations with the yields higher than $5.5 \mathrm{t}$ ha-1 contain hybrid combinations with complex resistance to diseases and pests, which were created on the basis of our self-pollinating donor lines resistant to entomo- and phytopathogens, confirms the principles formulated by us as to selecting parental pairs. The high yielding group includes, in particular, simple hybrids based on such valuable donors of complex resistance to pests and diseases as UKh 405, MA 22, UKhK 409, SM 5-1-1, F 502.

Table 4. Generalized distribution of corn breeding material by resistance to harmful organisms, (\%) (2015-2017).

\begin{tabular}{llcllll}
\hline \multirow{2}{*}{ Harmful organism } & \multicolumn{3}{c}{ Self-pollinating line } & \multicolumn{3}{c}{ Simple hybrids } \\
& High & Average & Low & High & Average & Low \\
Frit fly & 22.0 & 50.0 & 28.0 & 15.1 & 52.3 & 32.6 \\
Corn borer & 42.0 & 40.0 & 18.0 & 29.1 & 32.6 & 36.0 \\
Corn smut & 80.0 & 6.0 & 14.0 & 45.3 & 23.3 & 31.4 \\
Loose smut & 54.0 & 8.0 & 38.0 & 43.0 & 20.9 & 36.1 \\
\hline
\end{tabular}

The effectiveness of our selection work on search for donors with complex resistance is also confirmed by the overall evaluation of self-pollinating lines and simple corn hybrids (Table 4), in particular, and on the basis of the criteria identified in the research work, which made it possible to recommend the most valuable and, what is more important, the most stable of them to be used in selection. It can be seen from the presented data that self-pollinating lines and simple corn hybrids demonstrated a low percentage of resistance to damage by frit fly as just 22.0 and $15.1 \%$ were highly resistant, respectively.

The most uniform distribution was recorded in resistance to damage by a corn borer, high resistance to which showed $42.0 \%$ of self-pollinating lines and $29.1 \%$ of simple hybrids.

A significant number of self-pollinating lines had high resistance to corn smut $(80.0 \%)$ and loose smut (54.0\%). There were fewer highly resistant hybrid combinations to these diseases: 45.3 and $43.0 \%$, respectively.

It should be noted that about one-third (31.4 and 36.1\%) of simple hybrids were characterized by low resistance to these diseases. The possibility and effectiveness of combining high yields and resistance to pests and diseases in one genotype are evidenced by the results of the study of the correlations between yield inheritance and resistance to harmful organisms of simple hybrids, depending on their parental forms (Table 5).

The data indicate that the highest correlation was observed between hybrid offspring and the average value for maternal and paternal forms $(g=0.508 ; 0.638)$. The correlation of average force is established due to the significant effect of heterosis by this trait and, consequently, by the large magnitude of grain productivity of hybrids in comparison with their parental forms and lower correlation dependence.

Studying the correlation dependence for resistance to the corn borer between hybrids and their maternal and parental forms and average indicators between parental components, a close relationship was established between the mean values of maternal and parental forms by hybrid offspring $(\mathrm{g}=0.926 ; 0.907)$ and correlations of average force between hybrids and parental $(\mathrm{g}=0.638$; $0.592)$ and maternal ( $g=0.574 ; 0.595)$ forms.

Thus, in order to obtain corn borer resistant hybrids, it is necessary to select both parental forms resistant to this pest, which is proved by a fairly close correlation and the results of our previous analysis.

Table 5. Correlations between inheritance of yielding capacity and resistance to pathogens in hybrids and their parental forms, 2016-2017.

2016

2017

Indicator

\begin{tabular}{|c|c|c|c|c|c|c|c|c|c|c|c|}
\hline 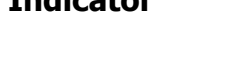 & $\mathbf{F 1 -}+$ & & $\mathbf{F 1 -}+$ & & $\begin{array}{l}\mathbf{F 1}+\sigma^{\lambda} \\
\mathbf{2}\end{array}$ & & $\mathbf{F 1 -}+$ & & F1- & & $\begin{array}{l}\mathbf{F 1}+{ }^{\lambda} \\
\mathbf{2}\end{array}$ \\
\hline Yielding capacity & $\begin{array}{l}0.262 * \\
0.131\end{array}$ & \pm & $\begin{array}{l}0.404 \\
0.124\end{array}$ & \pm & $\begin{array}{l}0.508 \\
0.117\end{array}$ & \pm & $\begin{array}{l}0.463 \\
0.120\end{array}$ & \pm & $\begin{array}{l}0.373 \\
0.126\end{array}$ & \pm & $\begin{array}{l}0.638 \\
0.104\end{array}$ \\
\hline Corn borer & $\begin{array}{l}0.574 \\
0.111\end{array}$ & \pm & $\begin{array}{l}0.638 \\
0.104\end{array}$ & \pm & $\begin{array}{l}0.926 \\
0.051\end{array}$ & \pm & $\begin{array}{l}0.595 \\
0.109\end{array}$ & \pm & $\begin{array}{l}0.592 \\
0.109\end{array}$ & \pm & $\begin{array}{l}0.907 \\
0.051\end{array}$ \\
\hline Frit fly & $\begin{array}{l}0.495 \\
0.118\end{array}$ & \pm & $\begin{array}{l}0.671 \\
0.100\end{array}$ & \pm & $\begin{array}{l}0.890 \\
0.061\end{array}$ & \pm & $\begin{array}{l}0.390 \\
0.125\end{array}$ & \pm & $\begin{array}{l}0.754 \\
0.089\end{array}$ & \pm & $\begin{array}{l}0.874 \\
0.066\end{array}$ \\
\hline Corn smut & $\begin{array}{l}0.582 \\
0.110\end{array}$ & \pm & $\begin{array}{l}0.492 \\
0.118\end{array}$ & \pm & $\begin{array}{l}0.821 \\
0.077\end{array}$ & \pm & $\begin{array}{l}0.524 \\
0.115\end{array}$ & \pm & $\begin{array}{l}0.629 \\
0.105\end{array}$ & \pm & $\begin{array}{l}0.881 \\
0.064\end{array}$ \\
\hline Loose smut & $\begin{array}{l}0.552 \\
0.113\end{array}$ & \pm & $\begin{array}{l}0.379 \\
0.125\end{array}$ & \pm & $\begin{array}{l}0.711 \\
0.095\end{array}$ & \pm & $\begin{array}{l}0.527 \\
0.115\end{array}$ & \pm & $\begin{array}{l}0.351 \\
0.127\end{array}$ & \pm & $\begin{array}{l}0.671 \\
0.101\end{array}$ \\
\hline
\end{tabular}

Note* - The insignificant correlation coefficient is shown 
Regarding the hybrids inheritance of resistance to damage by a frit fly, there is a strong correlation between the hybrids and both parental forms $(g=0.890 ; 0.874)$, which also requires the selection of both parental forms that are highly resistant to damage by this pest to obtain identical hybrid offspring. The correlation between the inheritance of resistance of hybrid combinations against the corn smut damage from their parental forms showed that the highest bond was observed between the hybrids and both parental forms $(g=0.821 ; 0.881)$ whereas hybrids and maternal forms $(g=0.582 ; 0.524)$ and hybrids and parental forms $(g=0.492$; 0.629 ) established average force bonds.

\section{Conclusion}

Thus, under the conditions of monocropping, there was a significant damage of the susceptible lines by loose smut. What is more, the corncobs had even worse damage, which significantly affected the yield of these lines. Therefore, the evaluation of lines and hybrids for resistance to loose smut under conditions of enhanced provocative background is a very important step in the selection of disease resistant hybrids. To increase the effectiveness of assessing the resistance of lines and hybrids to this disease in the conditions of the Right-Bank Forest Steppe of Ukraine, where the disease has not become widespread, it is necessary to use an artificial provocative background. The resistance of hybrids to corn smut depends on the number of parental forms resistant to the disease. The study of the degree of resistance inheritance to loose smut by determining the correlation dependence of resistance between hybrids and their parental forms showed that the highest correlation was established between hybrids and the average of both parental forms $(\mathrm{g}=0.711 ; 0.671)$, as well as between hybrids and maternal forms $(\mathrm{g}=0.552 ; 0.527)$.

The findings indicate a close dependence of hybrids on both parental forms, as well as the superiority of maternal inheritance.

To obtain corn hybrids resistant to loose smut, it is necessary to select both parental forms that are high yielding and resistant to pests and diseases, as indicated by the correlation between simple hybrids and the average value of parental forms ( $g=0.508$; 0.926), according to the relevant characteristics. Hence, the results presented in this section have made it possible to outline the basic principles for the selection of parental pairs to create hybrids both high-yielding and comprehensively resistant to the main pests and diseases. The identified sources of resistance according to the conducted correlation analysis have confirmed their overall effectiveness in hybrid combinations. The indicated self-pollinating lines, which are classified as valuable and promising from the point of view of their further use in breeding practice to create hybrids resistant to entomo- and phytopathogens, will be recommended for prospective study and use.

The conducted studies became the basis for the development of practical recommendations and improvement of the method for determining corn resistance to pathogens of corn smut and loose smut.

\section{References}

Barlog P. (2008). Effect of Mineral Fertilization on Yield of Maize Cultivars Differing in Maturity Scale. Acta Sci. Pol. Agricultura. Vol. 7, No. 5. - P. 5-17.

Bidgoli A. M., Akbari G. A, Mirhadi M. J., Zand E., Soufizadeh S. (2006). Path analysis of the relationships between seed yield and some morphological and phenological traits in safflower (Carthamus tinctorius L.). Euphytica, 148: 261-268. [CrossRef] [Direct Link] Butenko A. O., Sobko M. G., Ilchenko V. O., Radchenko M. V., Hlupak Z. I., Danylchenko L. M., Tykhonova O. M. (2019). Agrobiological and ecological bases of productivity increase and genetic potential implementation of new buckwheat cultivars in the conditions of the Northeastern Forest-Steppe of Ukraine. Ukrainian Journal of Ecology, 9 (1), - P. 162-168.

Didur I. M., Tsyhanskyi V. I., Tsyhanska O. I., Malynka L. V., Butenko, A. O., Klochkova, T. I. (2019). The effect of fertilizer system on soybean productivity in the conditions of right bank forest-steppe. Ukrainian Journal of Ecology, 9 (1), - P. 76-80.

FAO. (2011). The state of the world's land and water resources for food and agriculture (SOLAW). (FAO, Rome and Earthscan, London). [Google Scholar]

Kashiani P. G., Saleh N. A. (2010). Estimation of genetic correlations on sweet corn inbred lines using SAS mixed model. Am. J. Agric. Biol. Sci., 5, - P. 309-314. CrossRef | Direct Link |

Kashiani P. G. Saleh N. A., Abdullah P., Abdullah S. N. (2010). Variation and genetic studies on selected sweet corn inbred lines. Asian J. Crop Sci., 2, - P. 78-84. CrossRef | Direct Link |

Kolisnyk O. M. (2016). Resistance of self-pollinating corn lines to ustilago zeae is phacelothecareilina. Materials of the International Conference "Genetic Science and Education", Vinnytsia, - P. 134-137.

Kolisnyk O. M., Butenko A. O., Malynka L. V., Masik I. M., Onychko V. I., Onychko T. O., Kriuchko L. V., Kobzhev O. M. (2019). Adaptive properties of maize forms for improvement in the ecological status of fields. Ukrainian Journal of Ecology, 2019, 9 (2), - P. 33-37.

Kolisnyk O. M., Liubar V. A. (2007). Resistance of corn source material to corn smut. Feed and feed production, 61, - P. 40-45.

Kolisnyk O. M., Vatamaniuk O. V. (2010). Resistance of self-pollinating corn lines to Ustilago zeae Beck. Grain storage and processing, 8 (134), - P. 28-30.

Malik H. N., Malik S. I., Hussain, M. S., Chughtai U. R., Javad H. I. (2005). Genetic correlation among various quantitative characters in maize (Zea mays L.) hybrids. J. Agric. Soc. Sci., 1, - P. 262-265. Direct Link

Malosetti M., Ribaut J. M., Vargas M., Crossa J., Van Eeuwijk F. A. (2008). A multi-trait multi-environment QTL mixed model with an application to drought and nitrogen stress trials in maize (Zea mays L.). Euphytica, 161, - P. 241-257. CrossRef I

Mazur V. A., Kolisnyk O. M. (2016). Assessment of self-pollinating corn lines and hybrids of different growing season for resistance to diseases and pests in conditions of Right Bank Forest-Steppe. Agriculture and Forestry, 4, - P. 28-30.

Meng Q, et al. (2011). Alternative cropping systems for sustainable water and nitrogen use in the North China Plain. Environ. Ecosyst. Agric.;146, - P. 93-102. doi: 10.1016/j.agee.2011.10.015. [CrossRef] [Google Scholar]

Menkir A. (2008). Genetic variation for grain mineral content in tropical-adapted maize inbred lines. Food Chem., 110, - P. 454-464. CrossRef |

Mohammadi S. A., Prasanna B. M., Singh N. N. (2003). Sequential path for determining interrelationships among grain yield and related characters in Maize. Crop Sci., 43, - P. 1690-1697. Direct Link

Palamarchuk V. D., Mazur V. A., Zozulia O. L. (2009). Corn: selection and cultivation of hybrids. Vinnytsia, 199 p.

Palamarchuk V., Telekalo N. (2018). The effect of seed size and seeding depth on the components of maize yield structure. Bulgarian Journal of Agricultural Science, 24(5), - P. 783-790. 
Palamarchuk V. D, Klymchuk O. V., Polishchuk I. S., Kolisnyk O. M. (2010). Ecological, biological and technological principles of growing field crops. Vinnytsia, $680 \mathrm{p}$.

Scherner A., Melander B., Kudsk P. (2016). Vertical distribution and composition of weed seeds within the plough layer after eleven years of contrasting crop rotation and tillage schemes. Soil and Tillage Research. Elsevier BV. 3, $161: 135$. doi.10.1016/j.still.2016.04.005.

Shiferaw B., Prasanna B., Hellin J., Bänziger M. (2011). Crops that feed the world 6. Past successes and future challenges to the role played by maize in global food security. Food Secur. 3, 307-327. https://doi.org/10.1016/j.agee.2011.10.015

Talebi R., Fayaz F., Jelodar N. A. B. (2007). Correlation and path coefficient analysis of yield and yield components of chickpea (Cicer arietinum L.) under dry land condition in the West of Iran. Asian J. Plant Sci., 6, - P. 1151-1154. CrossRef | Direct Link |

Tanchik S. P. (2009). Efficiency of farming systems in Ukraine. Bulletin of Agrarian Science. № 12. - P. 5-11.

Tester M., Langridge P. (2010). Breeding technologies to increase crop production in a changing world. Science 327, - P. 818-822. [PubMed] [Google Scholar]

Thornton P. K., van de Steeg J., Notenbaert A., Herrero M. (2009). The impacts of climate change on livestock and livestock systems in developing countries: A review of what we know and what we need to know. Agr. Syst.;101:113-127. doi: 10.1016/j.agsy.2009.05.002. [CrossRef] [Google Scholar]

Tilman D., Balzer C., Hill J., Befort B. L. (2011). Global food demand and the sustainable intensification of agriculture. Proc. Natl. Acad. Sci. USA 108, - P. 20260-20264. [PMC free article] [PubMed] [Google Scholar]

Troyer A. F. (2004). Background of U.S. hybrid corn: II. Breeding, climate, and food/A.F. Troyer // Crop Science. - Vol. 44, № 2. P. 370-380.

Ivanov M. I., Rutkevych V. S., Kolisnyk O. M., Lisovoy I. O. (2019). Research of the influence of the parameters of the block-portion separator on the adjustment range of speed of operating elements. INMATEH - Agricultural Engineering. - Vol. 57/1. P. 37-44.

Tsiuk O. A. (2013). The theoretical rationale and development of the ecological farming system in the forest-steppe zone of Ukraine: abstract of the dissertation for a degree of the Candidate of Agricultural Sciences: spec. 06.01.01 "General Farming". P. 41.

Tsyhanskyi V. I., Didur I. M., Tsyhanska O. I., Malynka L. V., Butenko A. O., Masik I. M., Klochkova T. I. (2019). Effect of the cultivation technology elements on the activation of plant microbe symbiosis and the nitrogen transformation processes in alfalfa agrocoenoses. 2227-9555 e-ISSN 2226-3063 ISSN Modern Phytomorphology 13: - P. 30-34. doi.org/10.5281/zenodo.20190107 Yang D, et al. (2017). Analysis of reason for recent slowing maize yield increase under climate change in China. Trans. Chin. Soc. Agric. Eng.; 33, - P. 231-238. [Google Scholar]

Zozulia A. L. (1983). Anatomical and morphological methods for evaluating the selection material of corn. Selection and seed production of corn, 55, - P. 27-30.

\section{Citation:}

Kolisnyk, O. M., Onopriienko, V. P., Onopriienko, I. M., Kandyba, N. M., Khomenko, L. M., Kyrychenko, T. O., Tymchuk, D. S., Tymchuk, N. F., Terokhina, N. O. (2020). Study of correlations between yield inheritance and resistance of corn self-pollinating lines and hybrids to pathogens. Ukrainian Journal of Ecology, 10(1), 220-225.

(cc) EY This work is licensed under a Creative Commons Attribution 4.0. License 